Bull. Mater. Sci., Vol. 21, No. 4, August 1998, pp. 303-308. C Indian Academy of Sciences.

\title{
Phase instabilities during Ti-nitride precipitation in nitrogen implanted Ti-6AI-4V alloy
}

\author{
N RAJAN, T S SAMPATH KUMAR, K G M NAIR* and K KRISHAN ${ }^{\dagger}$ \\ Department of Nuclear Physics, University of Madras, Guindy Campus, Madras 600025 , India \\ * Materials Science Division, Indira Gandhi Centre for Atomic Research, Kalpakkam 603 102, India \\ ${ }^{\dagger}$ National Research and Technology Consortium, Parwanoo 173220 , India
}

MS received 18 December 1997; revised 5 May 1998

\begin{abstract}
Grazing incidence X-ray diffraction, performed on a $70 \mathrm{keV}$ nitrogen implanted Ti-6Al-4V system, reveals phase instabilities, during the course of nitride formation. With the build up of unbound $\mathbf{N}$ atom concentration, for a dose of $1 \times 10^{16}$ ions $/ \mathrm{cm}^{2}$, the surface region becomes $\alpha$-rich, whereas, on precipitation of Ti-nitrides at a high dose of $1 \times 10^{17}$ ions $/ \mathrm{cm}^{2}$, the $\beta$-Ti phase reappears, at the surface and beyond the implanted zone. The low concentration of $V$ and the strain in the nitrided zone, have led to radiation induced martensitic transformation of the $\beta$-Ti phase.
\end{abstract}

Keywords. Phase instabilities; nitrogen implantation; X-ray diffraction.

\section{Introduction}

The two-phase Ti-6Al-4V alloy finds wide use in a number of areas. Its use for aviation and space applications are well known. The past two decades have witnessed widespread use of the material for artificial joint prosthesis. An increase in the use of the material has been possible because of its advantages such as high strength to weight ratio, creep rupture properties and excellent biocompatibility (Bennet et al 1980; Hubler and Macafferty 1980; Buchanan et al 1987; Qiu et al 1991; Rieu et al 1992). Because of its poor tribological properties, $\mathrm{Ti}$ and its alloys are subjected to surface engineering (Qiu et al 1991; Rieu et al 1992), to improve the service life and performance. Nitrogen implantation in these systems has shown a promising path for the successful increase (Buchanan et al 1987) in their service life and some important studies are available on processing details for nitride precipitation (Hohmuth and Rauschenbach 1985; Elder et al 1989). A more detailed understanding of the evolution of the surface structure of this two-phase alloy during nitrogen implantation appears desirable. Clearly the surface and sub-surface matrix structure (Rieu et al 1992) and composition are expected to dictate the wear and corrosion properties.

Combinations of various implantation parameters, such as beam current, use of elevated temperature and multiple energy implantation, could possibly be controlled to produce a variety of surface properties. It is to be noted

*Author for correspondence that there is no straightforward recipe for an optimum dose or concentration profile for the best service life and performance. Along with these, considerable difficulties exist in the identification of the nature of the compounds formed and their chemical bonding with the various elements in the alloy. Possible existence of nitrides (Qiu et al 1990) as Ti(V)N is reported in the literature. Copious precipitation of $\beta$-Ti precipitates during $\mathrm{MeV}$ ion irradiation of $\mathrm{Ti}-6 \mathrm{Al}-4 \mathrm{~V}$ are known (Wang et al 1982; Plumton et al 1987). The $\beta$-Ti precipitates, thus formed are believed to owe their origin to radiation induced segregation (RIS) phenomenon. The mechanism of transport of undersized solutes towards sinks (Okamoto and Rehn 1979), operates in the segregation phenomenon. Likewise, complex phase instabilities are expected to arise during low energy room temperature implantation of a reactive species, such as nitrogen, which also stabilizes the $\alpha$-Ti phase. It is important to understand the evolution of the surface matrix under build up of nitrogen concentration. The present work deals with the preliminary investigation of $\mathrm{N}^{+}$implantation induced phase instabilities in $\mathrm{Ti}-6 \mathrm{Al}-4 \mathrm{~V}$ alloy containing deformed $\beta$-Ti, arising out of thermomechanical treatment. The use of grazing incidence $\mathrm{X}$-ray diffraction (GIXD), permits depth resolved structural information (Marra et al 1979; Arnaud and Brunel 1988-89), surface and sub-surface phase identification by varying the incident angle. Systematic GIXD studies were performed on samples, irradiated to two different doses of nitrogen, one representing a low peak concentration and the other a sufficiently high concentration leading to precipitation of nitrides. 


\section{Experimental}

Ti-6Al-4V (RT-31, MIDHANI, India; composition given in wt\%) sheets of $4 \mathrm{~mm}$ thickness, cut into coupons of $1 \times 1 \mathrm{~cm}^{2}$ were used in the study. Surface preparation involved mechanical polishing using silicon carbide papers of grit 400 through 1000 , followed by ultrasonic cleaning and final polishing with diamond paste. An optically flat surface was obtained. The samples were cleaned using distilled water and acetone and were thoroughly degreased using trichloroethylene before implantation.

Nitrogen ion $\left(\mathrm{N}^{+}\right)$implantation was carried out using a low energy accelerator. The energy used was $70 \mathrm{keV}$ and the beam was mass analysed. A low beam current of $1.25 \mu \mathrm{A}$ was maintained to avoid heating of the sample. Implantation was carried out at room temperature under ultra high vacuum conditions. Samples were implanted to two doses, viz. $1 \times 10^{16}$, and $1 \times 10^{17}$ ions $/ \mathrm{cm}^{2}$. The projected range and the concentration profile were computed using TRIM (Biersack and Haggmark 1980), Monte Carlo code and is shown in figure 1 for a typical dose of $1 \times 10^{17} \mathrm{ions} / \mathrm{cm}^{2}$.

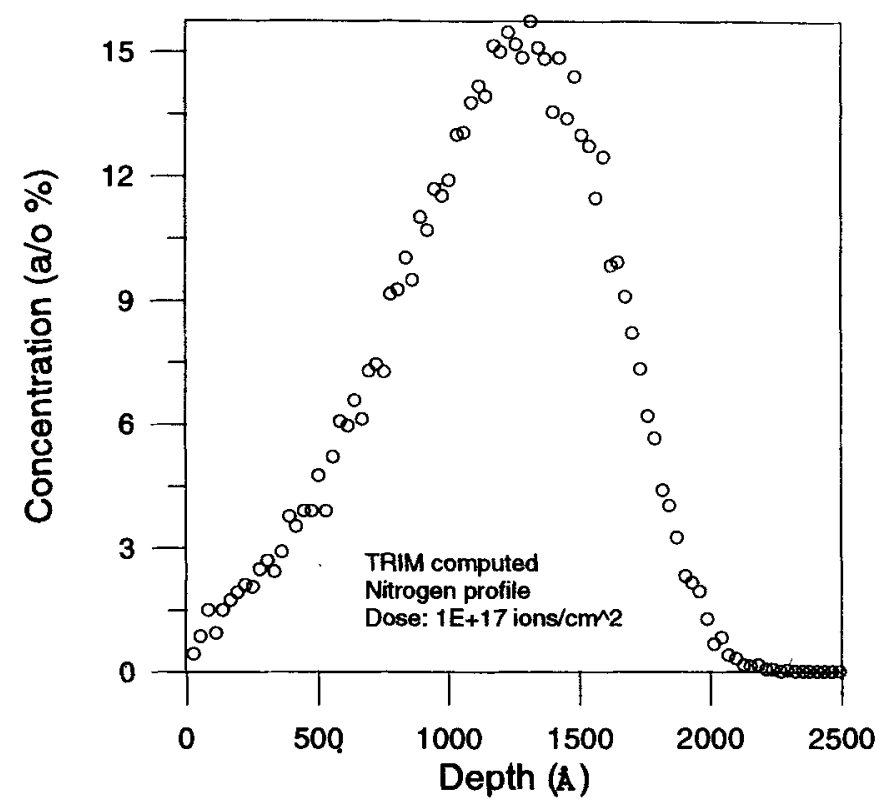

Figure 1. TRIM computed nitrogen concentration profile for $70 \mathrm{keV}$ nitrogen implantation in $\mathrm{Ti}-6 \mathrm{Al}-4 \mathrm{~V}$ alloy.

Table 1. X-ray penetration depth in Ti-6Al-4V alloy.

\begin{tabular}{lc}
\hline $\begin{array}{l}\text { Incident angle } \\
\text { (deg) }\end{array}$ & $\begin{array}{c}\text { Penetration depth } \\
(\AA)\end{array}$ \\
\hline 0.5 & 796 \\
$1 \cdot 0$ & 1,926 \\
$2 \cdot 0$ & 4,020 \\
$3 \cdot 0$ & 5,686 \\
$5 \cdot 0$ & 8,041 \\
\hline
\end{tabular}

The as-received alloy was characterized by $\mathrm{X}$-ray diffraction (XRD) and optical microscopy. GIXD was carried out using a Siemens D500 X-ray diffractometer with $\mathrm{CuK}_{\alpha}$ radiation. The incident angle $\theta_{i}$ was varied from $0.5^{\circ}$ to $10^{\circ}$. The computed penetration depth of $\mathrm{X}$-rays for various $\theta_{\mathrm{i}}$ in $\mathrm{Ti}-6 \mathrm{Al}-4 \mathrm{~V}$ alloy is listed in table 1 .

\section{Results and discussion}

Ti-6Al-4V is a two-phase system, comprising hcp $\alpha$-Ti and the bcc $\beta$-Ti phase. The $\beta$ transus of this system is $995^{\circ} \mathrm{C}$. The high temperature $\beta$-Ti phase is stabilized to exist at room temperature through alloying with substitutional $\beta$ stabilizing elements such as $\mathrm{V}, \mathrm{Mo}, \mathrm{Fe}, \mathrm{Cr}$, $\mathrm{Mn}$ and $\mathrm{Ni}$.

Figure 2 shows the XRD pattern of the as-received Ti-6Al-4V alloy. The $\beta$-Ti(110) line is observed, convoluted with the $\alpha$-Ti(1011) line. The inset in figure 2 shows the deconvoluted components. The presence of a retained $\beta$-Ti phase in a highly deformed and strained state is perceived from the broad hump like $\beta$-Ti(110). Unstable $\beta$-Ti phase arises out of rapid cooling or quenching from high temperature. This will result in a retained $\beta$ - $\mathrm{Ti}$ with lower $\mathrm{V}$ content (Akmoulin et al 1994) and remains unstable and susceptible to further transformations. A stable retained $\beta$-Ti phase with larger $\mathrm{V}$ concentration can be obtained by annealing.

Partial GIXD scans in the range $37^{\circ}-43^{\circ}$ are shown in figures 3,4 and 6 , for various irradiation doses, as well as for different incident angles $\theta_{\mathrm{i}}: 0.5^{\circ}-10^{\circ}$. The figures represent a series of transformations with dose and depth. Figure 3 represents the partial GIXD scans for the unirradiated sample. The $\alpha$-Ti(0002) and $\alpha$-Ti (1011) lines are seen at $38.577^{\circ}$ and $40.559^{\circ}$, respectively

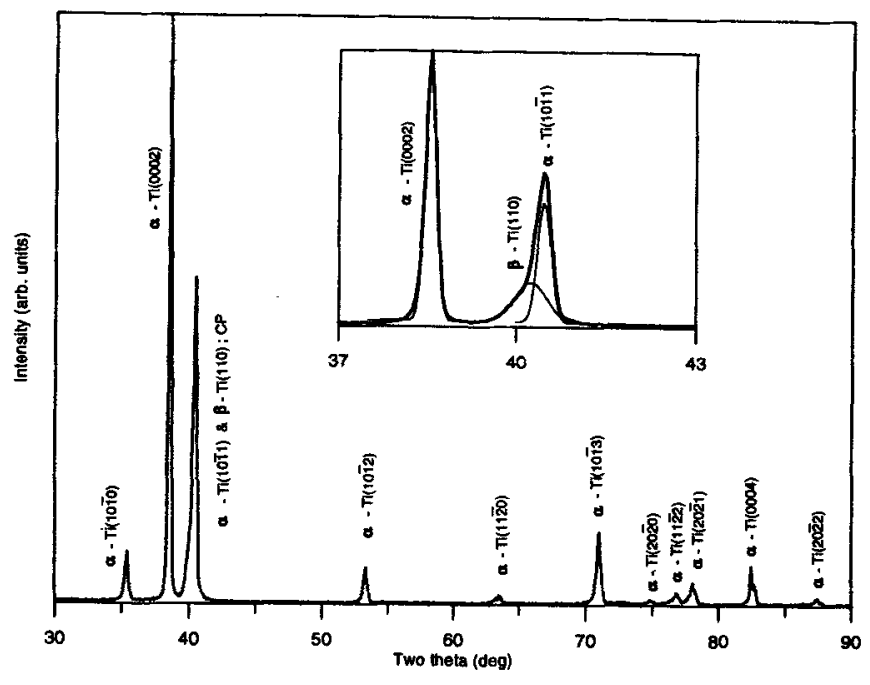

Figure 2. XRD of as-received Ti-6Al-4V alloy. The inset shows the deconvoluted components. 
for a $\theta_{i}$ of $10^{\circ}$. The $\alpha-\operatorname{Ti}(10 \overline{1} 1)$ peak is asymmetric owing to the convolution of the $\beta$-Ti(110) peak. Deconvolution of this convoluted peak (CP) into gaussians reveals a broad hump for $\beta$-Ti(110) with a large full width at half maximum (FWHM) of 0.56. This is essentially an outcome of the microstructure with unstable and non-uniformly strained $\beta$-Ti phase. The asymmetry involved in the $\mathrm{CP}$ and the ratio (A1/A2) of integrated intensities: $\mathrm{I}[\alpha-\operatorname{Ti}(10 \overline{1} 1)] /[/ \beta-\operatorname{Ti}(110)]$ shown in figure 7

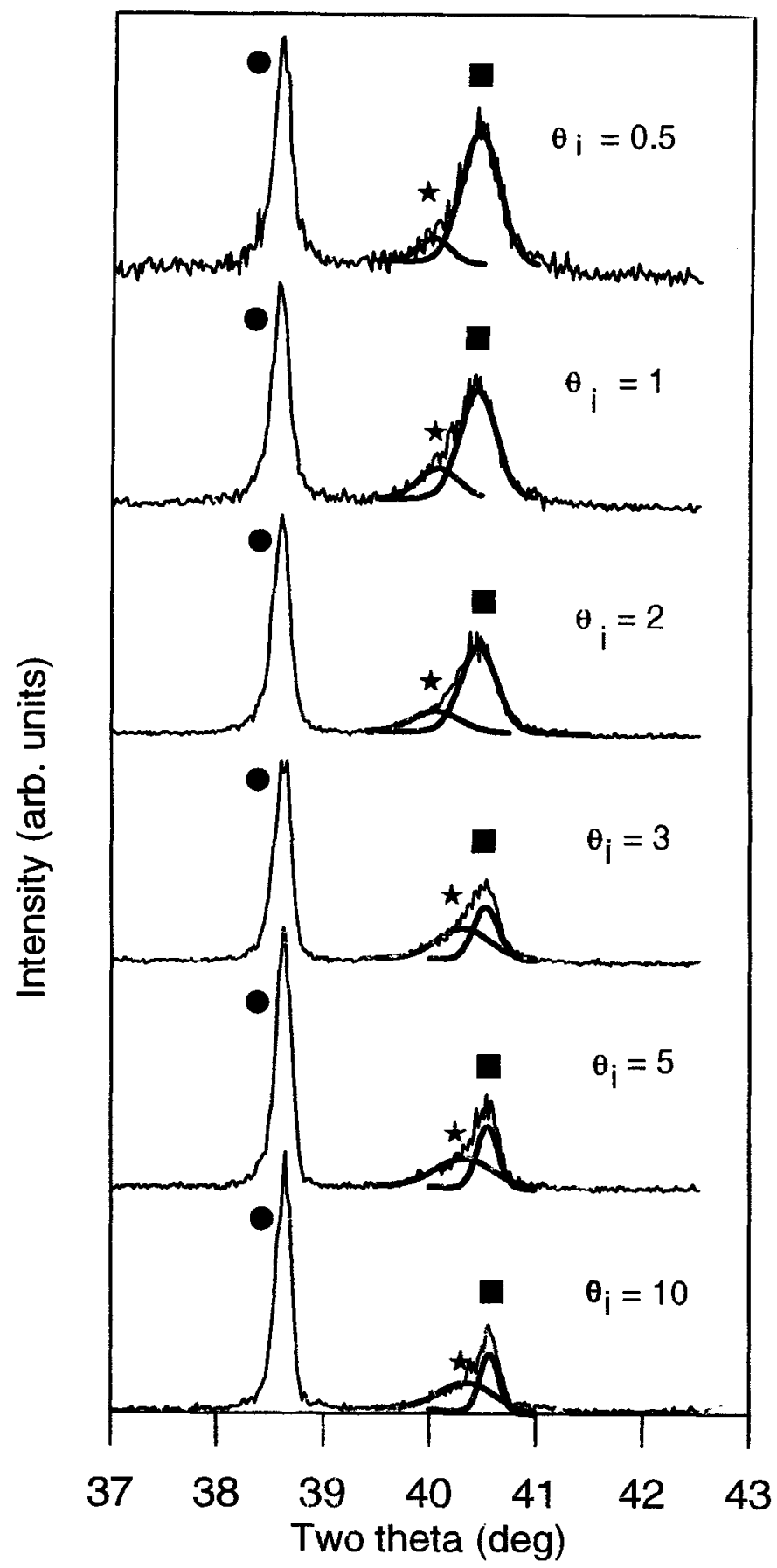

Figure 3. Partial GIXD scans of unirradiated Ti-6Al-4V alloy. $(\bullet, \alpha-\operatorname{Ti}(0002) ; \star, \beta-\operatorname{Ti}(110) ; \mathbf{D}, \alpha$-Ti(1011)), for samples irradiated to various doses, bring out most of the information regarding the relative abundance of phases and their instabilities under $\mathrm{N}^{+}$irradiation. Figure 3 for the unirradiated case shows minor structural variations with depth. The CP shows a greater degree of asymmetry for $\theta_{i}: 10^{\circ}, 5^{\circ}$ and $3^{\circ}$. The symmetry, however, is improved for lower $\theta_{i}: 0 \cdot 5^{\circ}-2^{\circ}$. Changes in FWHM and intensity of the convoluted components are seen. The intensity of $\beta-\operatorname{Ti}(110)$ is low for higher $\theta_{\mathrm{i}}$. However,

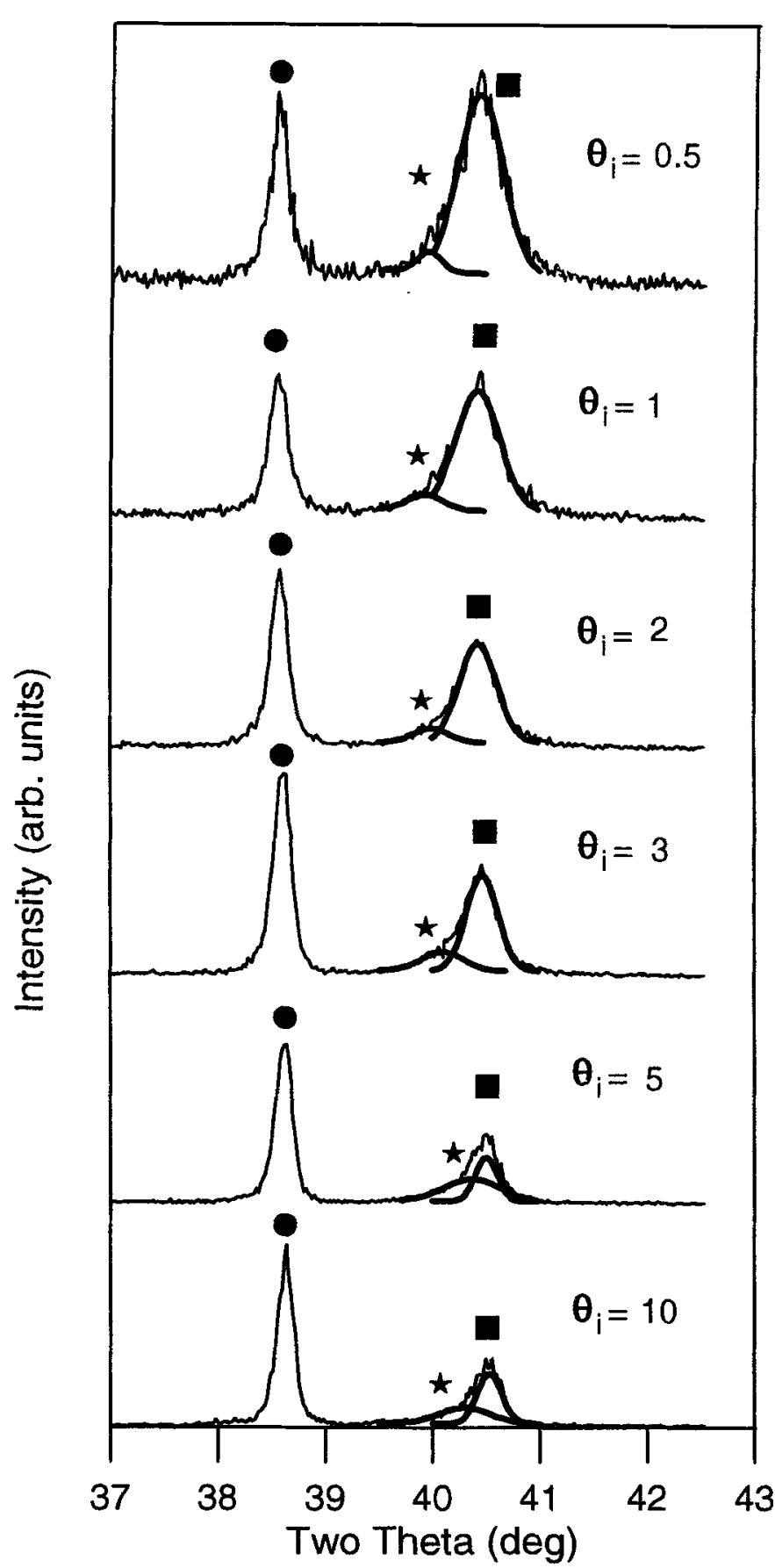

Figure 4. Partial GIXD scans of $1 \times 10^{16}$ ions $/ \mathrm{cm}^{2} \mathrm{~N}^{+}$implanted Ti-6Al-4V alloy. ( $\bullet, \alpha-\operatorname{Ti}(0002) ; \star, \beta-\operatorname{Ti}(110) ; \boldsymbol{\alpha}, \alpha-\operatorname{Ti}(1011))$. 
the integrated intensity is much larger in comparison with the near surface cases. The ratio A1/A2 for the unirradiated case shown in figure 7 , shows an increase in the $\beta$-Ti phase volume fraction with depth, which finally stabilizes thereafter to bulk constituents. The surface, thus appears to be $\alpha$-rich. There is a possibility of carbon and oxygen contamination, which are $\alpha$ stabilizers. These are difficult to be removed completely unless sputter eroded in situ before implantation. The results characterize the unirradiated material surface and is useful to compare the changes produced in the surface and sub-surface regions after implantation.

Figure 4 represents the partial GIXD scans for various $\theta_{i}$ of the $1 \times 10^{16}$ ions $/ \mathrm{cm}^{2}$ irradiated sample. A peak concentration of 1.76 a/o at a mean depth of $1195 \AA$ (TRIM computed value) is introduced into the system. Best fit and deconvolution of the CP show a rise in the intensity and FWHM of the $\alpha$-Ti( $(10 \overline{1} 1)$ peak and a simultaneous fall in the $\beta$-Ti(110) intensity. This is already apparent from the peaks with improved symmetry for $\theta_{i}: 0.5^{\circ}-2^{\circ}$. The ratio A1/A2 for the $10^{16}$ ions $/ \mathrm{cm}^{2}$ irradiated sample in figure 7 shows a clear and enormous increase, implying an $\alpha$-phase rich surface zone. There is approximately a linear rapid increase in the $\alpha$-Ti volume fraction, from bulk to surface. Since $\mathrm{N}$ is an $\alpha$-stabilizing agent, its concentration build up must have stabilized more $\alpha$ volume fraction. The vanadium, stabilizing $\beta$-Ti could have possibly undergone a transport away from the nitrided zone, or its concentration is simply not sufficient to stabilize the $\beta$-Ti phase, which was previously present. The $\beta-\operatorname{Ti}(110)$ peak is also observed to have shifted towards lower $2 \theta$ value, implying

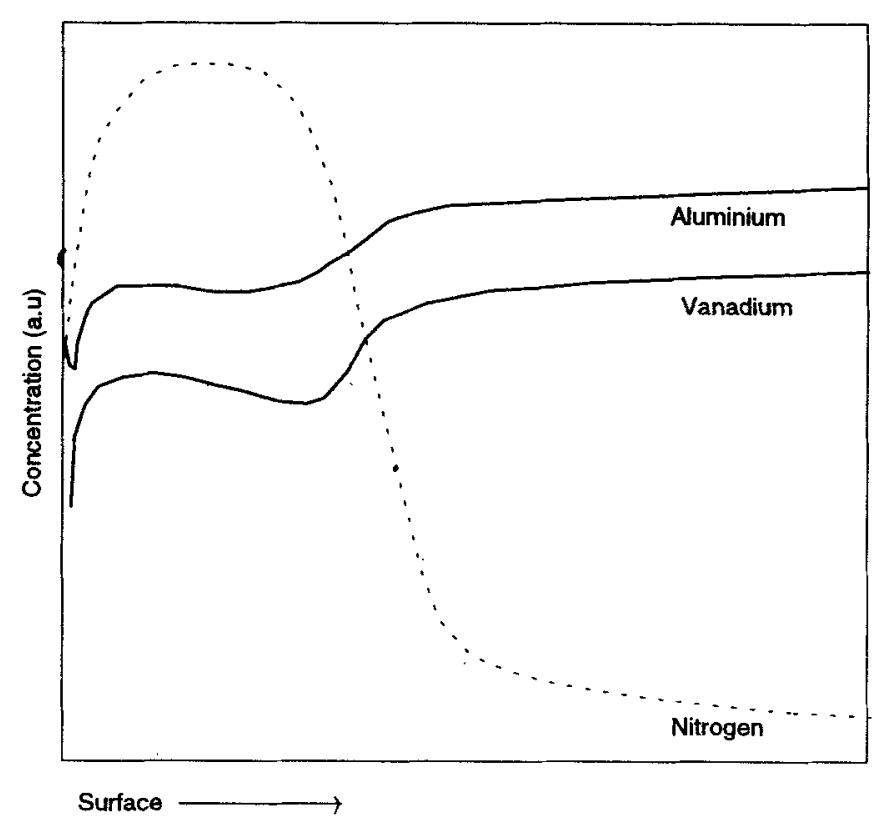

Figure 5. Schematic plot representing $\mathrm{Al}$ and $\mathrm{V}$ depletion due to high dose nitrogen implantation in $\mathrm{Ti}-6 \mathrm{Al}-4 \mathrm{~V}$ alloy. a 'de-stabilized' $\beta$-Ti (Akmoulin et al 1994). In an earlier study by Adami et al (1994), depletion of vanadium was seen in $\mathrm{N}^{+}$implanted $\mathrm{Ti}-6 \mathrm{Al}-4 \mathrm{~V}$ alloy for a dose of $5 \times 10^{16}$ ions $/ \mathrm{cm}^{2}$ and above. The $V$ concentration at the surface region is therefore, not sufficient to stabilize the previously present $\beta$-Ti volume fraction. A schematic depicting vanadium and aluminium depletion due to high

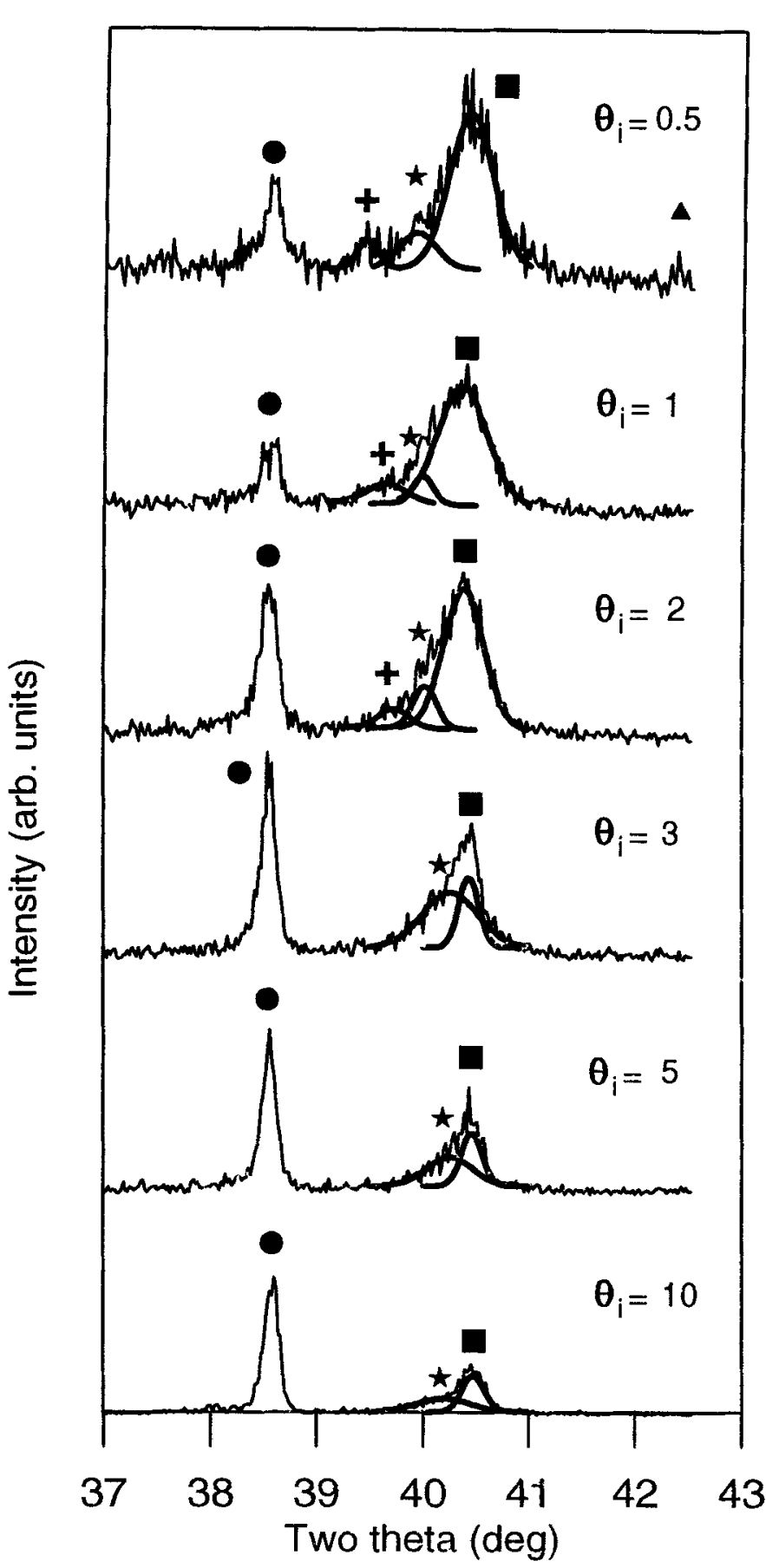

Figure 6. Partial GIXD scans of $1 \times 10^{17}$ ions $/ \mathrm{cm}^{2} \mathrm{~N}^{+}$implanted Ti-6Al-4V alloy. $(\bullet, \alpha$-Ti(0002); $\star, \beta$-Ti(110); $\boldsymbol{a}, \alpha$-Ti(1011); +, $\varepsilon-\mathrm{Ti}_{2} \mathrm{~N}(111) ; \boldsymbol{\Delta}, \delta$-TiN(200)). 
dose of nitrogen implantation (from literature) is shown in figure 5. The combined effect of the presence of nitrogen atoms and a vanadium depleted zone (Rajan et al 1997) is the reason for the observed increase in $\alpha$-phase.

Figure 6 represents, for various $\theta_{i}$, the partial GIXD scans of the sample irradiated to a dose of $1 \times 10^{17}$ ions $/ \mathrm{cm}^{2}$. The peak nitrogen concentration is estimated to be around $15.22 \mathrm{a} / \mathrm{o}$. The concentration is well above the solubility limit at room temperature, and leads to precipitation. The GIXD pattern at $\theta_{i}=0.5^{\circ}$ shows the presence of the tetragonal $\varepsilon-\mathrm{Ti}_{2} \mathrm{~N}$. The peaks are very broad owing to large amounts of strain and disorder introduced by the high dose $\mathrm{N}$ implantation. At this high dose, the intensity of $\beta$-Ti(110) line has increased for $\theta_{i}=0.5^{\circ}$. The shift of the $\beta$-Ti(110) line towards lower $2 \theta$ was intermediate with respect to unirradiated and $1 \times 10^{16}$ ions $/ \mathrm{cm}^{2}$ irradiated samples. From figure 7 , it can be inferred that there is a clear re-appearance of $\beta$-Ti phase at the surface. The ratio A1/A2 falls below the value for the unirradiated case. The increase in the $\beta$-Ti volume fraction at surface is expected to have arisen owing to $\mathrm{V}$ enrichment implying transport of $\mathrm{V}$ towards the surface. Also the presence of $\beta-\mathrm{Ti}$ in the nitrided zone is considerable as observed from figures 4 and 6 . This can be attributed to the absence of enough unbound $\mathrm{N}$ atoms, which have already participated as nitrides. Likewise, one can observe a highly asymmetric $\mathrm{CP}$ for $\theta_{\mathrm{i}}=3^{\circ}$, in comparison with the $1 \times 10^{16}$ ions $/ \mathrm{cm}^{2}$ and the unirradiated case. The contribution of intensity to the $\mathrm{CP}$ is more by $\beta$-Ti(110) as can be deduced from

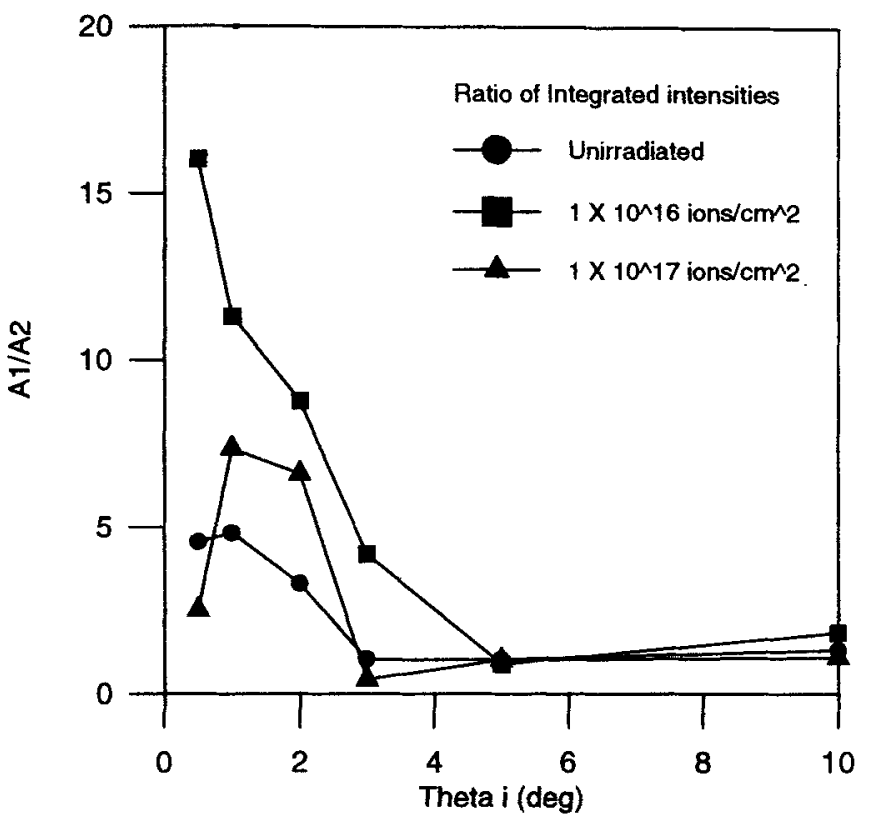

Figure 7. Ratio of integrated intensities A1/A2: $\mathrm{I}[\alpha-\mathrm{Ti}(10 \overline{1} 1)] /$ I[ $\beta$-Ti(110)]. deconvolution. A rise in the ratio $\mathrm{A} 1 / \mathrm{A} 2$ for $\theta_{\mathrm{i}}: 1^{\circ}$ and $2^{\circ}$ and a fall for $0.5^{\circ}$ and $3^{\circ}$ above and below, respectively, in comparison with the unirradiated case is clearly seen. This suggests depletion of $\mathrm{V}$ atoms in the nitrided zone as well as transport of $\mathrm{V}$ towards surface and pile-up zone beyond the implanted layer (Rajan et al 1997), as it is otherwise not possible to stabilize a larger $\beta$-Ti volume fraction which is seen from the relatively intense $\beta$-Ti peaks at $0.5^{\circ}$ and $3^{\circ}$ incident angles. The depletion of $\mathrm{V}$ and the other alloying element $\mathrm{Al}$ in 30 and $80 \mathrm{keV}$ implantation of $\mathrm{N}$ atoms, in the implanted zone has been reported (Adami et al 1994) previously. Depletion of $\mathrm{V}$ and $\mathrm{Al}$ was also observed in an r.f. plasma nitrided (Raveh 1993) Ti-6Al-4V alloy in the nitrided zone. RIS of $\mathrm{V}$ atoms towards free surface during $\mathrm{MeV}$ irradiation of V (Wang et al 1982) or Al (Plumton et al 1987) at high temperatures have also been reported in earlier literature. However, RIS has remained difficult to identify in reactive $\mathrm{N}^{+}$implantation in earlier studies (Qiu et al 1991), owing to surface and near-surface modification using low energies. The presence of an oxide layer and other contaminations have probably made this observation difficult. In any case, further studies are required in order to understand the phenomenon. The consequence of this result can be important when one considers applications such as in artificial joint prosthesis (Qiu et al 1991; Rieu et al 1992), as there exists the possible release of toxic $\mathrm{V}$ atoms into the body environment (Adami et al 1994) with passage of time. The presence of $\mathrm{V}$ and $\mathrm{Al}$ in the passive oxide layer under corrosion conditions has also been reported. However, the transport of $\mathrm{Al}$ or its depletion has not shown any direct manifestation in the $\mathrm{X}$-ray diffraction patterns since $\mathrm{Al}$ as well as $\mathrm{N}$ are $\alpha$-phase stabilizers.

In figure 6 , a split in the $\alpha$-Ti(0002) peak is observed for $\theta_{i}=1^{\circ}$. This splitting is possibly due to the formation of $\alpha^{\prime \prime}$ martensite. A complete scan over the $2 \theta$ range $30^{\circ}-90^{\circ}$, with better time step, has revealed splitting of peaks $\alpha$-Ti(0002), $\alpha$-Ti( $10 \overline{1} 1)$ and $\alpha$-Ti(10 $\overline{1} 2)$, characteristic (Akmoulin et al 1994) of the $\alpha^{\prime \prime}$ martensite. The $\mathrm{V}$ depleted region containing unstable $\beta$-Ti might easily undergo shearing of the lattice under the existing strain in the nitrided zone, leading to the formation of the martensite. The $\alpha^{\prime \prime}$ martensite formation is strongly composition dependent and is known to occur in Ti-Mo as well as in Ti-Al-V systems. The formation of radiation induced martensite in $\mathrm{N}^{+}$implanted zone in $\mathrm{Ti}-6 \mathrm{Al}-4 \mathrm{~V}$ alloy is being reported for the first time, though there are a number of studies on the transformation of $\beta$-Ti to martensite $\alpha^{\prime \prime}$ phase during thermal treatment and mechanical deformation (Akmoulin et al 1994). Radiation induced martensite has also been observed in other systems, such as $\mathrm{Fe}-10 \mathrm{Cr}-15 \mathrm{Ni}$ (James 1990) as well as in type 304 stainless steel (Chayahara et al 1991), previously. Likewise stress or deformation induced 
martensites (Niinomi et al 1990; Akmoulin et al 1994) have been observed in Ti-6 $\mathrm{Al}-4 \mathrm{~V}$ system as well as in other $(\alpha+\beta)$ Ti systems. The low concentration of $\mathrm{V}$ in the nitrided zone can be the reason for not sustaining the stabilization of the $\beta$-Ti phase under irradiation, which leads to the diffusionless transformation to $\alpha^{\prime \prime}$. The deformed $\beta-\mathrm{Ti}$ in the as-received alloy is expected to favour these transformations. Probably, this might not be the case in a microstructure containing equiaxed $\alpha$ with intergranular $\beta$. Further studies are being conducted to understand the complex evolution of the surface and sub-surface phases during $\mathrm{N}^{+}$implantation in Ti-6Al-4V alloy.

\section{Conclusion}

Ti-6Al-4V alloy is found to experience nitrogen implantation induced phase instabilities. The surface zone turns out to be $\alpha$-rich at a dose of $1 \times 10^{16}$ ions $/ \mathrm{cm}^{2}$. At a high dose of $1 \times 10^{17}$ ions $/ \mathrm{cm}^{2}$, the $\beta$-Ti phase is found to reappear at the surface and beyond the implanted zone, significantly. Vanadium seems to undergo transport and gets depleted in the implanted layer. The low concentration of vanadium in the strained nitrided zone has led to radiation induced martensitic transformation of $\beta$ to $\alpha^{\prime \prime}$.

\section{Acknowledgements}

One of the authors (NR) thanks Prof. Ajay Gupta, IUC-DAEF, Indore for providing the GIXD facility. The Council of Scientific and Industrial Research (CSIR), New Delhi, is acknowledged for providing financial assistance in the form of a fellowship.

\section{References}

Adami $\mathrm{M}$ et al $1994 X$ Int. conf. IIT-94, Catania, Italy (eds) S Coffa, G Ferla, F Priolo and E Rimini, p. 889

Akmoulin I A, Niinomi M and Kobayashi T 1994 Met. Metall. Trans. A25 1655

Arnaud Y and Brunel M 1988-89 Appl. Surf. Sci. 35345

Bennet M J, Houlton M R and Dearnaley G 1980 Corr. Sci. 2069

Biersack J P and Haggmark L G 1980 Nucl. Instrum. \& Meth. 174257

Buchanan R A, Rigney E D and Williams J M 1987 J. Biomed. Mater. Res. 21355

Chayahara A, Nakashima S, Hashimoto M, Sasaki T, Kurokawa, Kiyama M S and Satou M 1991 Nucl. Instrum. \& Meth. B59/60 893

Elder J E, Thamburaj R and Patnaik P C 1989 Surf. Eng. 555

Hohmuth K and Rauschenbach B 1985 Mater. Sci. \& Eng. 69489

Hubler G K and Macafferty E 1980 Corr. Sci. 20103

James F 1990 Met. Metall. Trans. A21 1823

Marra W C, Eisenberger P and Cho A V 1979 J. Appl. Phys. 50927

Ninomi M, Kobayashi T, Inagaki I and Thompson A W 1990 Met. Metall. Trans. A21 1733

Okamoto P R and Rehn L E $1979 \mathrm{~J}$. Nucl. Mater. 832

Plumton D L, Kulcinski G L and Dodd R A 1987 J. Nucl. Mater. 144264

Qiu X, Conrad J R, Dodd R A and Worzala F J 1990 Metall. Trans. A21 1663

Qiu, X, Dodd R A, Conrad J R. Chen A and Worzala F J 1991 Nucl. Instrum. \& Meth. B59/60 951

Rajan N, Sampath Kumar T S, Tyagi A K, Rajagopalan S, Nair K G M and Krishan K 1997 Proc. DAE Solid State Phys. Symp. India C40 404

Raveh A 1993 Mater. Sci. \& Eng. A167 155

Rieu J, Pichat A, Rabbe L M, Rambert A, Chabrol C and Robelet M 1992 Mater. Sci. \& Tech. 8589

Wang Z, Ayrault G and Wiedersich H 1982 J. Nucl. Mater. $108 \& 109331$ 